\title{
HOW SUCCESSFUL YOU HAVE BEEN IN LIFE DEPENDS ON THE RESPONSE SCALE USED: THE ROLE OF CULTURAL MINDSETS IN PRAGMATIC INFERENCES DRAWN FROM QUESTION FORMAT
}

\author{
Ayse K. Uskul \\ University of Essex \\ Daphna Oyserman and Norbert Schwarz \\ University of Michigan
}

Spike W. S. Lee and Alison Jing Xu

University of Toronto

\begin{abstract}
To respond to a question, respondents must make culturally relevant, context-sensitive pragmatic inferences about what the question means. Participants in a culture of modesty (China), a culture of honor (Turkey), and a culture of positivity (U.S.) rated their own (Study 1) or someone else's (their parents or people their parents' age, Study 2) success in life using either a rating scale that implied a continuum from failure to success $(-5$ to +5$)$ or varying degrees of success (0 to 10). As predicted, culture and rating format interacted with rating target to influence response patterns. Americans, sensitive to the possibility of negativity, rated all targets more positively in the bipolar condition. Chinese were modesty-sensitive, ignoring the implications of the scale, unless rating strangers for whom modesty is irrelevant. Turks were honor-sensitive, rating themselves and their parents more positively in the bipolar scale condition and ignoring scale implications of rating strangers.
\end{abstract}

Ayse K. Uskul is now at the University of Kent.

We are grateful to Maggie Phillips, Andrea Coombes, and Alexandria Glispie in the United States and Hale Bolak Boratav, Zeynep Catay, Zeynep Uskul Engin, and Zafer Uskul in Turkey for their help in data collection. We also appreciate the support provided by the Social Science and Humanities Research Council of Canada (postdoctoral fellowship, Uskul), the Regula Herzog Young Investigator's Award in Survey Research, Institute for Social Research, University of Michigan (Uskul), and the Alexander Von Humboldt Foundation (Oyserman).

Address correspondence to Ayse K. Uskul, University of Kent, School of Psychology, Keynes College, Room A2.12, Canterbury, Kent CT2 7NP United Kingdom. E-mail: a.k.uskul@kent.ac.uk or to Daphna Oyserman, 426 Thompson, Institute for Social Research, University of Michigan, Ann Arbor, MI 48019-1248. E-mail: Daphna.Oyserman@umich.edu. 
"How successful have you been in life?" To answer this question, research participants have to go beyond the literal meaning of the question to determine what the person asking the question wants to know in context, that is, the question's pragmatic meaning. To make sense of a question's pragmatic meaning, participants draw on the context of the question, including the format of response alternatives (for a review see Schwarz, 1999). To date, pragmatic inference processes in research situations have primarily been investigated with Western samples (Schwarz, 1994, 1996). However, cultural psychological perspectives suggest that cultural differences in chronically accessible meaning-making lenses or mindsets should interact with contextual features of questionnaires in shaping respondents' answers (for discussions, see Oyserman, 2011; Schwarz, Oyserman, \& Peytcheva, 2010; Uskul \& Oyserman, 2006). The present research addresses the possibility that pragmatic inferences are based on an interaction between the meanings made salient in a culture and the meanings made salient in a questionnaire setting. This way, it explores the influence of the communicative context on question responding as an example of the situated, interactive, and adaptive aspects of social cognition.

To do so, we draw on research demonstrating that the pragmatic meaning drawn from a particular feature of a questionnaire (the numeric values used in rating scales) influences inferred meaning and therefore survey response. We briefly review this literature and integrate its implications within a cultural perspective, predicting that chronically accessible cultural differences between cultures of positivity (e.g., the U.S.), cultures of honor (e.g., Turkey), and cultures of modesty (e.g., China) will interact with question content and features of response alternatives to influence response.

\section{THE PRAGMATIC MEANING OF NUMERIC VALUES OF RATING SCALES}

A situated cognition approach emphasizes pragmatics as a central concern of language use (Smith \& Semin, 2004, 2007). One implication is that individuals take into account the intentions of the communicators and shape their responses accordingly. In support of this approach, in everyday conversations, if pragmatic meaning is unclear, it can be clarified; conversation partners can ask if they are not sure what the other meant (Grice, 1975; Sperber \& Wilson, 1995). In research settings, participants cannot ask for clarification either because their "partner" is present only via a self-administered questionnaire or because their "partner" is an interviewer instructed to maintain a standardized script. This leaves research participants to rely on contextual features of the questionnaire for clarification.

Returning to the opening example, suppose that research participants are asked to report on their success in life along a rating scale anchored at "not at all successful" and "extremely successful." To provide a response, they have to determine the intended meaning of these anchors. Does "not at all successful" refer to the absence of outstanding achievements or to the presence of serious failures? Schwarz and colleagues (Schwarz, \& Hippler, 1995; Schwarz, Knäuper, Hippler, Noelle-Neumann, \& Clark, 1991) demonstrated that each of these interpretations is possible depending on the numeric values associated with the verbal anchors. Participants were randomly assigned to respond either on a unipolar rating scale that ranged from 0 to 10 or on a bipolar rating scale that ranged from -5 to +5 . To 
assess the effect of rating scale, all responses were recoded to 0 to 10 and mean success in life by response condition compared. Results showed a pronounced impact of scale format despite the use of same verbal anchors. Respondents rated themselves as more successful in life if randomly assigned to the bipolar scale $(M$ $=7.3)$ than if randomly assigned to the unipolar scale $(M=6.4)$. This was due to more frequent use of the bottom half of the scale when the scale ranged from 0 to 10 ( $34 \%$ of responses) than when the scale ranged from -5 to +5 ( $13 \%$ of responses).

Why might this be? Schwarz and colleagues (Schwarz et al., 1991; Schwarz \& Hippler, 1995) demonstrated in follow-up experiments that numeric values affected participants' interpretation of the term "not at all successful." When this label was combined with the numeric value " 0 ," participants interpreted it to reflect the absence of outstanding achievements. However, when the same label was combined with the numeric value "-5" and the scale offered " 0 " as the mid-point, they interpreted "not at all successful" as meaning the opposite of success, namely, the presence of explicit failures. Thus, consistent with a situated cognition approach (Smith \& Semin, 2004, 2007), pragmatic meaning was dynamically created from context. In this case, the context was the seemingly "formal" feature of using a bipolar vs. a unipolar rating scale.

Schwarz and colleagues (1991) observed this influence of bipolar vs. unipolar scale formats for participants' self-reports as well as reports about the success of their parents; in both cases, participants were reluctant to use the bottom half of the bipolar scale, resulting in more positive success ratings in this condition. Schwarz and colleagues concluded from this observation that the influence of the scale's numeric values is independent of the target to which the question pertained, as would be expected from a general shift in question meaning. The current studies revisit this conclusion. Two decades after the initial work, research in cultural psychology suggests that cultural differences in chronically accessible mindsets of positivity, modesty, and honor will interact with the meaning inferred from numeric values of scales in ways that depend on the target of the question. The current studies explore this possibility by asking American, Chinese, and Turkish participants to report on their own, their parents', or strangers' success in life. Next, we develop the rationale in more detail.

\section{CULTURAL MINDSETS}

There is increasing evidence to suggest that cultural mindsets influence how information is processed (for reviews see Nisbett, 2003; Oyserman, Coon, \& Kemmelmeier, 2002; Oyserman \& Lee, 2007, 2008a, b). Limited attention has been paid, however, to how cultural mindsets might impact cognitive and communicative processes underlying survey responding. As recently reviewed by Schwarz and colleagues (2010), a broad range of cultural mindsets may interact with formal features of questionnaires to influence survey response, shaping responses at different stages of the survey process, ranging from how a question is made sense of to how responses are edited and formatted. As a result, researchers would face the dilemma of not knowing whether respondents' answers reflect their true attitudes, values, and behaviors, differences in the response process, or an unknown mixture of both. It is therefore important to unfold the role of culture in questionnaire responding. Moreover it is important to go beyond the frequently examined com- 
parisons between individualistic and collectivistic mindsets, often limited to contrasting East Asian and Western participants. As reviewed elsewhere (Oyserman, Coon, \& Kemmelmeier, 2002; Oyserman \& Lee, 2007, 2008a, 2008b), East-West comparisons cannot be presumed to encompass all aspects of individualism and collectivism. As outlined next, of particular interest are the differences between collectivism that is modesty-based, as in East Asian contexts, and collectivism that is honor-based, as is the case in many other regions of the world.

Individualism has been described as a worldview in which individuals are the basic building blocks of society; each individual is conceived of as unique, responsible for his or her own fate and joining with one another when benefit is mutual (Markus \& Kitayama, 1991; Oyserman et al., 2002; Triandis, 1989). Perhaps for this reason, Americans, as a prototypical individualistic society, are socialized to focus on the positive and emphasize possible successes (see Becker \& Marecek, 2008). This preference for positivity applies to oneself and others. Americans tend to generally hold positive self-views (e.g., Baumeister, Tice, \& Hutton, 1989) and prefer information that maintains or enhances these positive self-views (e.g., Swann, Pelham, \& Krull, 1989). Americans also show more positive evaluation of family members (Endo, Heine, \& Lehman, 2000) and less critical evaluation of their children's performance (Stevenson \& Stigler, 1992) than East Asians. Lack of strong in- vs. out-group boundaries in individualistic cultures (e.g., Bond \& Smith, 1996; Iyengar, Lepper, \& Ross, 1999, Yamagishi \& Yamagishi, 1994) should result in an extension of this positivity to evaluations of non-close others as long as these evaluations are not in direct contrast to self-evaluations (Heine, 2007). Given the high salience of positivity focus, when evaluating themselves, close, and non-close others, American individuals should be motivated to avoid the low end of the bipolar scale ( -5 to 0$)$, which would communicate endorsement of failure. Thus, we predict that Americans would have more positive evaluations (higher ratings) on the bipolar scale compared to the unipolar scale, extending the scale effect that Schwarz and colleagues (1991) observed with German participants to evaluations of any target (self, parents, and strangers).

In contrast to the positivity encouraged by American socialization, East Asian collectivism highlights concerns about modesty (Suzuki \& Yamagishi, 2004; Yamaguchi, 1994). For example, Japanese are vigilant not to lose face via immodest presentations (Heine, Lehman, Markus, \& Kitayama, 1999) and prefer to focus on self-criticism rather than on personal achievements (Heine \& Lehman, 1995). Though these general effects are situated and East Asians can focus on either positivity or modesty depending on contextual cues (Lee, Oyserman, \& Bond, 2010), we assume that East Asians will be generally more oriented toward modesty. This motivation to be modest and not stick out should extend to how close others are presented, given the significant overlap in self-close other representations (for a review, see Kitayama, Duffy, \& Uchida, 2007). There is some support for this, in that Chinese, Japanese, and Korean parents, children, and teachers are each more critical in their reports about their child's, their own, and their pupils' academic successes than are Americans (Stevenson \& Stigler, 1992). The need for modesty for one's own and close other's accomplishments should not extend to all assessment; for example, modesty would not require more critical appraisal of non-close others who are not thought of as in-group members. Given the high salience of modesty concerns in East-Asian cultures, we expect the members of these cultures 
to endorse the low end of the bipolar scale, and thus presence of failure, as a way to communicate modesty when evaluating themselves and close others (but not non-close others). Thus, we predict no differences between the ratings on the bipolar vs. unipolar scales for self and close other evaluations, but for strangers we predict higher scores on the bipolar scale compared to the unipolar scale.

Rather than focusing on modesty, honor-based collectivism, more common in Latin American, Middle Eastern, and African contexts (Iliffe, 2005; Pitt-Rivers, 1965; Rodriguez Mosquera, Manstead, \& Fischer, 2000, 2002a, 2002b; Sev'er \& Yurdakul, 2001; Vandello \& Cohen, 2003; Vandello, Cohen, Grandon, \& Franiuk, 2009), focuses on maintenance of social and personal reputation (e.g., Cross, Uskul, Gercek-Swing, Sunbay, \& Ataca, 2012; Gregg, 2005, 2007; Rodriguez Mosquera et al., 2002a, 2002b; Uskul, Cross, Gercek-Swing, Sunbay, \& Ataca, 2012). Honor belongs to individuals but also to family members; the maintenance and protection of both individual and relational honor is strongly valued and encouraged (e.g., Kardam, 2005; Mojab \& Abdo, 2004; Pratt-Ewing, 2008; Uskul et al., 2012). Honor is lost if close others fail and enhanced if close others succeed (Gregg, 2005, 2007; Pitt-Rivers, 1977; Rodriguez Mosquera et al., 2000, 2002a; Stewart, 1994). Thus, within a collectivistic culture of honor, honor requires positive appraisal of one's reputational base (oneself and one's family members) and less positive appraisal of others (including strangers). Given the high level of preference for maintaining social reputation of the self and close others (but not non-close others) among individuals from cultures of honor, we predict less frequent use of the low end of the bipolar scale as a means to avoid endorsement of failure. Thus, when rating themselves and close others on important attributes, we predict members of honor cultures to produce higher ratings on the bipolar scale compared to the unipolar scale, but to show no difference between these two scales when rating strangers.

\section{THE PRESENT STUDIES}

In the current research we predict that the implication of pragmatic meaning for survey response will depend on cultural focus. To test this prediction, we sampled participants from a culture of positivity (the U.S.), a culture of modesty (China), and a culture of honor (Turkey, see Bagli \& Sev'er, 2003; Kagitcibasi, 1996; Kardam, 2005; Sev'er \& Yurdakul, 2001) and asked them to rate either themselves (Study 1) or their parents, and strangers (Study 2) on their "success in life" using response scales that implied either varying degrees of presence of success ( 0 to 10$)$ or varying degrees of failure and success $(-5$ to +5$)$. We expect that unless self-ratings are in direct contrast to other ratings, American positivity should extend to ratings of any target and that East Asian modesty and Turkish honor should extend to ratings of both self and close others but not to ratings of irrelevant targets such as strangers. Therefore, in the current studies, we use a between-subjects designparticipants rate either themselves or someone else- so as not to set up a contrast between self and other. 


\section{PILOT STUDY}

In a pilot study, we asked undergraduates in each of the three cultural groups $(n=$ 60 U.S., $n=74$ Turkey, and $n=70$ China) how desirable being "successful in life" was to them ( $1=$ not at all desirable, $7=$ very desirable). On average, responses were above the midpoint and did not vary by culture (MUS $=5.27, S D=1.18$; $\left.M_{\text {Turkey }}=5.36, S D=1.20 ; M_{\text {China }}=5.56, S D=1.06\right), F(2,201)=1.10, p=.34$. Thus, in each of the cultures, being successful is equally desirable, allowing us to proceed to our test of cultural effects on pragmatic inference drawn from scale format and question target while helping rule out a potential alternative explanation, that any differences found were due to differences in the importance or desirability of being successful in life.

\section{STUDY 1}

Participants were asked to evaluate how successful they had been in life on either a bipolar or unipolar scale. We predicted that cultural mindset (modesty, honor, positivity) would result in differing response patterns. We hypothesized that, when asked to evaluate their own personal success in life, Chinese would respond with more modesty than Turkish or American participants. More specifically, American and Turkish, but not Chinese participants, would provide more positive ratings of personal success in life when using a bipolar response scale than a unipolar response scale.

\section{METHOD}

Sample. Participants were undergraduates in the United States $(n=56$ European American, 33 women, $\left.M_{\text {age }}=19.9, S D=.97\right)$, Turkey $\left(n=40,36\right.$ women, $M_{\text {age }}=22.6$, $S D=2.00)$, and Hong Kong $\left(n=43,7\right.$ women, $\left.M_{\text {age }}=20.6, S D=1.58\right)$. The initial analyses with age as a covariate and gender as an additional factor did not show a main $\left(F_{\text {age }}<1 ; F_{\text {sex }}<1\right)$ or interaction effect (all possible $F \mathrm{~s}<1.56, p>.20$ ) involving these variables ${ }^{1}$; hence, age and gender are not included in the main analyses.

Design. In each sample, participants were randomly assigned to one of two conditions which differed in the response scale provided (bipolar -5 to +5 , or unipolar 0 to 10), and all responded to the same single question, "How successful have you been in life?" in their native language. ${ }^{2}$ Verbal scale anchors were the same in both conditions. Not at all successful was the low anchor (to -5 in the bipolar condition and to 0 in the unipolar condition) and very successful was the high anchor (to +5 in the bipolar condition and to 10 in the unipolar condition).

1. Future research is needed to examine potential gendered impact of honor-related norms with samples consisting of comparable number of male and female participants.

2. In this study, participants evaluated exclusively their own success in life. In addition to evaluating their own success, participants also rated themselves on the following attributes: nice, funny, exciting, fair, humanistic, unique, independent, calm, flexible, self-knowing, socially sensitive, traditional, complicated, determined, and warm. 


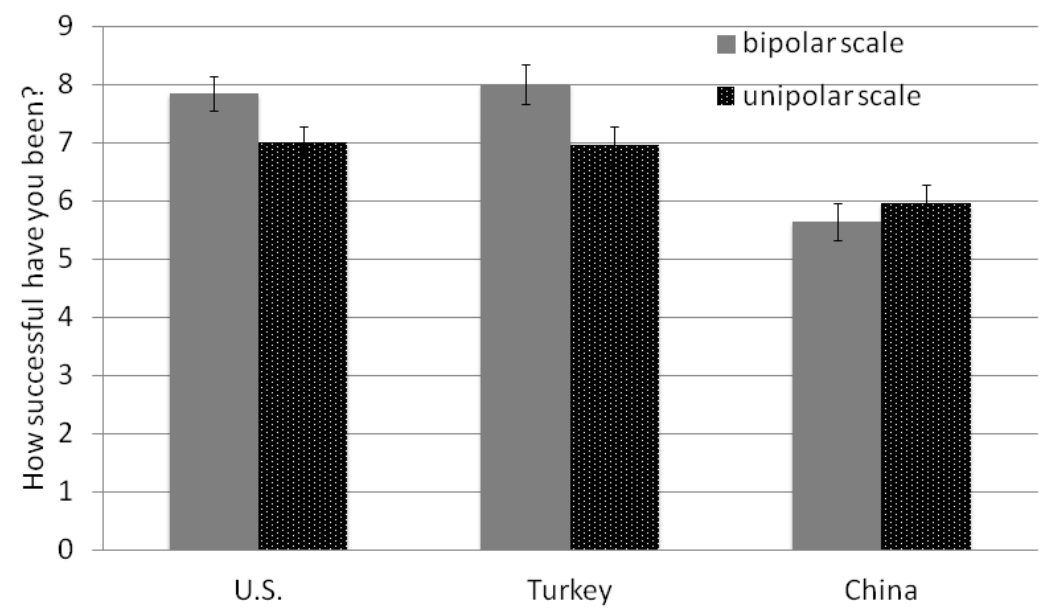

FIGURE 1. Mean personal success ratings as a function of type of numeric values used in rating scales and culture. Error bars represent standard errors of the mean.

\section{RESULTS AND DISCUSSION}

Responses in the bipolar condition were recoded so all responses ranged from 0 to 10 . As predicted, analysis of variance yielded a cultural group main effect $(F(2$, $133)=18.21, p<.001)$, a scale main effect $(F(1,133)=4.22, p=.04)$, and a country by scale interaction $\left(F(2,133)=2.65, p=.07, \eta^{2} p=.038\right.$, observed power $\left.=.52\right)$. These effects are presented graphically in Figure 1. With regard to cultural group main effect, as predicted, Chinese participants rated their own success more modestly $(M=5.79, S D=1.85)$ than either Turkish $(M=7.48, S D=1.13, d=1.10)$ or American participants $(M=7.38, S D=1.50, d=.94),(p s<.001)$, and Turkish and American participants did not differ from each other $(p=.86)$. Across countries, ratings were higher on the bipolar $(M=7.16, S D=2.02)$ than on the unipolar $(M=$ $6.63, S D=1.29, d=.31$ ) scale. As predicted, the effect of scale condition differed by country. Chinese participants maintained their modest response regardless of condition (unipolar $M=5.95, S D=1.47$; bipolar $M=5.64, S D=2.17, p=.49$ ). Turkish and American participants responded more positively on the bipolar (Turkish $M=$ $8.00, S D=1.03$; American $M=7.84, S D=1.75$ ) than on the unipolar (Turkish $M=$ $6.95, S D=1.00$, American $M=7.00, S D=1.15$ ) scale, both $p \mathrm{~s}<.05, d_{\mathrm{TR}}=1.03, d_{\mathrm{US}}=$ $.57 .{ }^{3}$ Results are consistent with the prediction that Chinese rate the self modestly, following a chronically accessible modesty mindset in China, whereas the chronically accessible mindsets in the United States and Turkey, positivity and honor, yield similarly positive responses when rating the self. A limitation of Study 1 is that it cannot rule out the possibility that Chinese participants were not sensitive to the pragmatic implications of the different scale formats. Study 2 addresses this

3. An examination of percentage of responses below the midpoint of the scale revealed a large cultural difference. Turks and Americans were less likely to choose below midpoint responses in the bipolar $\left(M_{\text {Turkish }}=0.00 \%, M U S=4.00 \%\right)$ than in the unipolar $\left(M_{\text {Turkish }}=10.00 \%\right.$, MUS $\left.=9.68 \%\right)$ condition. This was not the case for Chinese participants who chose below midpoint responses in both the bipolar $(M=40.91 \%)$ and unipolar $(M=38.10 \%)$ conditions. 
limitation by having participants rate close others and strangers. If Chinese are insensitive to the pragmatic implications of question format, the target should not matter. If they are sensitive to the pragmatic implications of question format, then target should matter. Specifically, a modesty mindset should apply only to evaluations of self and close others, not to evaluations of strangers. Accordingly, Chinese participants should rate self (Study 1) and close others (Study 2) modestly, but simply use the pragmatic inference drawn from the scale for strangers for whom the modesty interpretation is irrelevant.

\section{STUDY 2}

As in Study 1, in Study 2 participants were randomly assigned to rating scale condition within country. However, rather than rate their own success, participants were randomly assigned to either rate their parents' success in life or to rate the average success of people their parents' age. This latter target was chosen as a way of obtaining a rating about people who are clearly not connected to the self, but are a meaningful group-people of one's parents' generation, in each of the studied cultures. Our predictions follow our general model. First, Americans, following a positivity mindset, would continue to be sensitive to the inference drawn from the scale, rating all targets more positively on the bipolar scale than on the unipolar scale. Second, Turkish individuals, following an honor mindset, would rate their parents more positively and strangers more negatively on the bipolar scale. Third, Chinese, following a modesty mindset, would rate their parents modestly but should use the pragmatic inference drawn from the scale in the case of strangers since modesty norms are irrelevant in the case of strangers (one can neither boast nor be modest about strangers).

\section{METHOD}

Sample. Participants were undergraduates in the United States $(n=100$ European American, 50 women, $\left.M_{\text {age }}=20.54, S D=2.21\right)$, Turkey $\left(n=81,69\right.$ women, $M_{\text {age }}=$ $21.41, S D=2.00)$, and China $\left(n=102,64\right.$ women, $\left.M_{\text {age }}=20.06, S D=1.15\right)$. Initial analyses with age as a covariate and gender as an additional factor did not show any significant main $\left(F_{\text {age }}<1 ; F_{\text {sex }}(1,258)=2.55, p=.11\right)$ or interaction effects involving these variables (all possible $F_{\mathrm{s}}\langle 2.38, p>.10)^{1}$; age and gender are therefore not included in the main analyses.

Design. In each country sample, participants were randomly assigned to question target and response format in a $2 \times 2$ design. They were asked to respond either to "How successful have your parents been in life?" or "How successful have people at your parents' age been in life?" on either the bipolar $(-5$ to +5$)$ or unipolar (0 to 10) response format used in Study $1 .{ }^{4}$

\footnotetext{
1. Future research is needed to examine potential gendered impact of honor-related norms with samples consisting of comparable number of male and female participants.

4. The evaluations concerned the success of one's parents and people at one's parents' age only and did not include evaluations of one's own success. In addition to how successfully they have been, these targets were also evaluated on the following attributes: fair, flexible, unique, socially sensitive, cooperative, funny.
} 
Just as in Study 1, the verbal scale anchors (not at all successful, very successful) were the same across conditions and responses were recoded to range from 0 to 10 .

\section{RESULTS AND DISCUSSION}

Analysis of variance yielded a cultural group main effect $(F(2,271)=17.61, p<$ $.001)$, a scale main effect $(F(1,271)=19.35, p<.001)$, a question target main effect $(F(1,271)=12.19, p=.001)$, and the predicted country by scale condition by target interaction, $F(2,271)=2.88, p=.058, \eta 2 p=.021$, observed power $=.57$. These effects are presented graphically in Figure 2.

Overall, Chinese participants generally rated success more modestly $(M=6.59$, $S D=2.06)$ than either Turkish $(M=7.88, S D=1.90, d=.65)$ or American participants $(M=7.91, S D=1.54, d=.73)(p s<.001)$, and Turkish and American participants did not differ from each other $(p=.97)$. Across countries, ratings were higher in the bipolar $(M=7.92, S D=1.88)$ than in the unipolar $(M=6.94, S D=1.89, d=$ .52) scale condition. With regard to target, parents $(M=7.78, S D=2.01)$ were rated as more successful than strangers $(M=7.06, S D=1.81, d=.38)$. More important, these main effects were moderated by the predicted 3-way interaction of country, response target, and rating scale condition as detailed next by country.

The pattern of Chinese participants' ratings supports our prediction for a culture of modesty. In the parent target condition, Chinese rated their parents modestly and scale condition (unipolar $M=6.96, S D=1.79$, bipolar $M=6.83, S D=2.67, p=$ .78) did not matter. In the stranger condition, Chinese participants replicated the scale effect shown by Schwarz and colleagues (1991) and rated strangers more positively on the bipolar $(M=6.96, S D=1.55)$ than the unipolar $(M=5.67, S D=$ 1.92) scale $(p<.01, d=.57)$. The latter observation also implies that Chinese participants were sensitive to the numbers of the scale, but not influenced by them, when they rated their parents' or their own (Study 1) success.

The pattern of Turkish participants' ratings supports our predictions for a culture of honor. In the parent target condition, Turks rated their parents more positively on the bipolar scale (bipolar: $M=9.10, S D=.91$ ) than the unipolar scale (unipolar: $M=7.75, S D=2.29, p=.02, d=.77$ ). In the stranger condition, Turkish participants rated strangers more negatively and scale did not matter (unipolar: $M=7.15, S D=1.66$, bipolar: $M=7.34, S D=1.81, p=.49) .{ }^{5}$ Finally, the pattern of American participants' ratings supports our predictions for a culture of positivity. The effect of scale was independent of target for American respondents; they rated both parents (bipolar: $M=8.58, S D=1.36$, unipolar: $M=7.72, S D=1.74, p=.08, d$ $=.55$ ) and non-close others (bipolar: $M=8.525, S D=1.19$, unipolar: $M=6.75, S D=$ $1.11, p<.001, d=1.54)$ as more successful on the bipolar than on the unipolar scale.

\footnotetext{
5. An examination of percentage of responses below the midpoint of the scale revealed cultural differences. No matter what target they were rating, American participants always chose fewer below-midpoint responses in the bipolar than in the unipolar scale condition (parents: bipolar: $3.85 \%$, unipolar: $12 \%$; strangers: bipolar: $4 \%$, unipolar: $16.67 \%$ ). Turkish participants chose fewer below-midpoint responses in the bipolar than in the unipolar scale condition when rating parents (bipolar: $0 \%$, unipolar: 15\%), but not when rating strangers (bipolar: $14.26 \%$, unipolar: $15 \%$ ). Chinese participants chose fewer below-midpoint responses in the bipolar than in the unipolar condition when rating strangers (bipolar: 20.38\%, unipolar: 40.74\%), but not when rating parents (bipolar: $30.43 \%$, unipolar: $21.43 \%)$.
} 


\section{GENERAL DISCUSSION}

Numerous studies at the interface of social cognition and research methods explored what participants infer from research instruments (for reviews, see Schwarz \& Oyserman, 2011; Schwarz, 1994, 1996). Their findings highlighted the situated and context-sensitive nature of evaluative judgment, with important implications for social science measurement (Schwarz, 1999). However, this work has largely ignored the possibility that participants' inferences from research instruments may be moderated by cultural context. The present studies contribute to the scarce evidence bearing on this possibility (e.g., Ji, Schwarz, \& Nisbett, 2000; Haberstroh, Oyserman, Schwarz, Kühnen, \& Ji, 2002). We assumed that respondents from different cultures would be sensitive to the pragmatic implications of different scale formats in general, but would differ in the conditions under which they act on these implications. Consistent with Oyserman's (2011; Oyserman \& Sorensen, 2009) culture-as-situated-cognition model, we observed pronounced betweencountry differences that depended on who respondents were evaluating-themselves, their parents, or strangers.

The cultural psychological literature suggests that American contexts highlight positivity, and, indeed, American respondents were generally positive regardless of who they rated. When randomly assigned to a bipolar scale condition in which negative numbers imply the presence of negative outcomes, they were even more positive, independent of target (self, parent, stranger). Chinese and Turkish respondents were more nuanced, responding differently to the scale condition when rating self and parents than when rating strangers. The cultural psychological literature suggests that East Asian contexts highlight modesty-focused collectivism, whereas Turkish contexts highlight honor-focused collectivism. Indeed, Chinese respondents rated themselves and their parents more modestly and did not shift their responses upward when the pragmatic inference of the scale was that low numbers represented presence of failure. However, their ratings of strangers show that Chinese respondents were sensitive to the implications of the rating scale, but only followed them when the norm of modesty did not apply. Hence, Chinese participants rated strangers more positively on a bipolar than unipolar scale, but refrained from overly positive responses when they rated themselves or their parents. The reverse was true for Turkish respondents. Turkish respondents rated themselves and their parents more positively and observed the pragmatic implications of the bipolar scale by shifting their responses upward for these ingroup targets. However, strangers were not given the benefit of the pragmatic implications of the bipolar scale, and their success ratings remained low regardless of scale format. Thus, whether respondents did or did not act on the pragmatic implications of formal features of a questionnaire depended on the interplay of cultural mindset and question target.

Our findings also contribute to a more differentiated understanding of cultures that are commonly labeled as "collectivistic" by going beyond prior research contrasting Eastern collectivism and Western individualism; they underscore the need to heed differences between non-Western cultures, instead of assuming that findings from one non-Western society can be generalized to others (see Cohen, 2007, for a similar argument). Our approach also aligns with the recent conceptualization of the cultural logics of dignity, face, and honor systems by Cohen and col- 


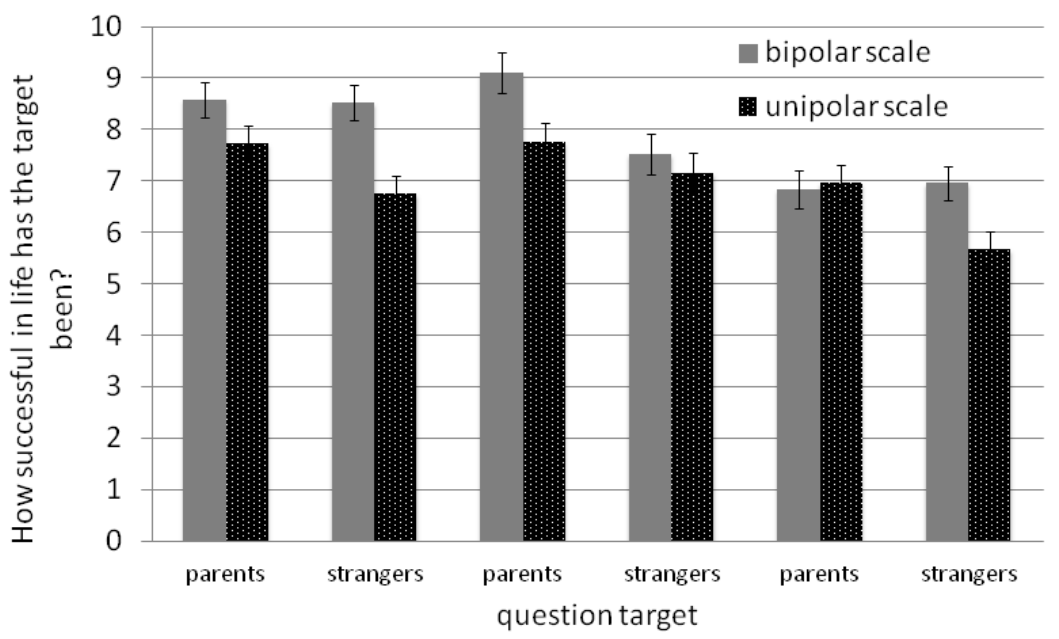

FIGURE 2. Mean success ratings as a function of type of numeric values used in rating scales, target of evaluation, and culture. Error bars represent standard errors of the mean.

leagues (Kim \& Cohen, 2010; Kim, Cohen, \& Au, 2010; Leung \& Cohen, 2011). In particular, as demonstrated here, collectivistic cultures that are modesty-based and those that are honor-based are likely to socialize members to make sense of themselves and their worlds differently. Our results also contribute to the understanding of self-presentational norms in honor-based cultures, where evidence is rather limited compared to what is known about self-presentational norms in Western individualistic and East Asian modesty-focused collectivistic cultures. As honor is likely to be experienced in relational terms in honor-based collectivistic cultures, positive self and close-other presentations can be useful means to achieve a respectable social standing. However, a respectable social standing may also be achieved by presenting those who are not part of the ingroup in a less positive light. While qualitative literature on the concept of honor in the Turkish context provides evidence in this direction, the current studies offer a systematic investigation of how self-presentational norms operate in relation to the self, ingroup members and outgroup members.

While we showed effects using cross-national comparisons, our methodological choice does not imply that cultural mindsets are fixed. Future research is needed to test the prediction that across societies, people will use positivity, modesty, or honor mindsets in responding to survey questions depending on which mindset is accessible at the time, due to contextual influences (Oyserman \& Lee, 2007). In either case, accessible mindset should interact with formal features of questionnaires in ways that depend on the target of the question. Such an approach would further contribute to the understanding of the situatedness of question answering in research contexts and help distinguish accessible mindset (primed by contextual cultural cues) from available mindset (that is, general cultural orientation) (Oyserman, 2011).

In sum, in line with principles of situated cognition (Smith \& Semin, 2004), our findings highlight the interplay of contextual cues, cultural norms, and target of judgment. On a practical note, they demonstrate that the impact of formal features 
of questionnaires (e.g., rating scale format) on participants' answers cannot be understood without taking participants' cultural mindset into account; conversely, the impact of cultural mindset on responses cannot be understood without taking into account the impact of formal features of questionnaires. To date these contingencies have received little attention despite growing concerns about cultural differences in survey response (e.g., Johnson \& van de Vijver, 2003; Lalwani, Shavitt, \& Johnson, 2006). Disentangling the complex interplay of culture, question content, and features of the research instrument poses a challenging task; unless we master it, we run the risk of misinterpreting context-sensitive culture effects in participants' reports as true cultural differences in actual judgment and behavior.

\section{REFERENCES}

Bagli, M., \& Sev'er, A. (2003). Female and male suicides in Batman, Turkey: Poverty, social change, patriarchal oppression and gender links. Women's Health and Urban Life, 2, 60-84.

Baumeister, R. F., Tice, D. M., \& Hutton, D. G. (1989). Self-presentational motivations and personality differences in self-esteem. Journal of Personality, 57, 547-579. doi:10.1111/j.1467-6494.1989.tb02384.x

Becker, D., \& Marecek, J. (2008). Dreaming the American dream: Individualism and positive psychology. Social and Personality Psychology Compass, 2, 1767-1780. doi:10.1111/j.1751-9004.2008.00139.x

Bond, R., \& Smith, P. B. (1996). Culture and conformity: A meta-analysis of the Asch (1952b, 1956) line judgment task. Psychological Bulletin, 119, 111-137. doi:10.1037/0033-2909.119.1.111

Cohen, D. (2007). Methods in cultural psychology. In S. Kitayama \& D. Cohen (Eds.), Handbook of cultural psychology (pp. 196236). New York: Guilford.

Cross, S., Uskul, A. K., Gercek-Swing, B., Sunbay, Z., \& Ataca, B. (2012). Confrontation vs. withdrawal: Cultural differences in responses to threats to honor. Group Processes and Intergroup Relations. Online ahead-of-print. doi: $10.1177 / 1368430212461962$

Endo, Y., Heine, S. J., \& Lehman, D. R. (2000). Culture and positive illusions in relationships: How my relationships are better than yours. Personality and Social Psychology Bulletin, 26, 1571-1586. doi:10.1177/01461672002612011
Gregg, G. S. (2005). The Middle East: A cultural psychology. New York: Oxford University Press.

Gregg, G S. (2007). Culture and identity in a Muslim society. New York: Oxford University Press.

Grice, H. P. (1975). Logic and conversation. In P. Cole \& J. L. Morgan (Eds.), Syntax and semantics: Speech acts (pp. 41-58). New York: Academic Press.

Haberstroh, S., Oyserman, D., Schwarz, N., Kühnen, U., \& Ji, L. (2002). Is the interdependent self more sensitive to question context than the independent self? Self-construal and the observation of conversational norms. Journal of Experimental Social Psychology, 38, 323-329.

Heine, S. J. (2007). Culture and motivation: What motivates people to act in the ways that they do? In S. Kitayama \& D. Cohen (Eds.), Handbook of cultural psychology (pp. 714-733). New York: Guilford.

Heine, S. J., \& Lehman, D. R. (1995). Cultural variation in unrealistic optimism: Does the West feel more invulnerable than the East? Journal of Personality and Social Psychology, 68, 595-607. doi:10.1037/00223514.68.4.595

Heine, S. J., Lehman, D. R., Markus, H. R., \& Kitayama, S. (1999). Is there a universal need for positive self-regard? Psychological Review, 106, 766-794. doi:10.1037/0033-295X.106.4.766

Iliffe, J. (2005). Honour in African history. New York: Cambridge University Press. 
Iyengar, S. S., Lepper, M. R., \& Ross, L. (1999). Independence from whom? Interdependence with whom? Cultural perspectives on ingroups versus outgroups. In D. Prentice \& D. Miller (Eds.), Cultural divides (pp. 273-301). New York: Sage.

Ji, L., Schwarz, N., \& Nisbett, R. E. (2000). Culture, autobiographical memory, and behavioral frequency reports: Measurement issues in cross-cultural studies. Personality and Social Psychology Bulletin, 26, 586-594. doi:10.1177/0146167200267006

Johnson, T. P., \& van de Vijver, F. J. R. (2003). Social desirability in cross-cultural research. In J. A. Harkness, F. J. R. van de Vijver, \& P. P. Mohler (Eds.), Cross-cultural survey methods (pp. 193-202). Hoboken, NJ: Wiley.

Kagitcibasi, C. (1996). Family and human development across cultures: A view from the other side. Hillsdale, NJ: Erlbaum.

Kardam, F. (2005). The dynamics of honor killings in Turkey. Ankara: Population Association, UNDP, and UNPF.

Kim, Y.-H., \& Cohen, D. (2010). Information, perspective, and judgments about the self in face and dignity cultures. Personality and Social Psychology Bulletin, 36, 537-550. doi:10.1177/0146167210362398

Kim, Y.-H., Cohen, D., \& Au, W.-T. (2010). The jury and abjury of my peers: The self in face and dignity cultures. Journal of Personality and Social Psychology, 98, 904916. doi:10.1037/a0017936

Kitayama, S., Duffy, S., \& Uchida, Y. K. (2007). Self as cultural mode of being. In S. Kitayama \& D. Cohen (Eds.), The handbook of cultural psychology (pp. 136-174). New York: Guilford.

Lalwani, A., Shavitt, S., \& Johnson, T. P. (2006). What is the relation between cultural orientation and socially desirable responding? Journal of Personality and Social Psychology, 90, 165-178. doi:10.1037/00223514.90.1.165

Lee, S. W. S. Oyserman, D., \& Bond, M. (2010). Am I doing better than you? That depends on whether you ask me in English or Chinese: Self-enhancement effects of language as a cultural mindset prime. Journal of Experimental Social Psychology, 46, 785-791. http://dx.doi. org/10.1016/j.jesp.2010.04.005.

Leung, A. K.-Y., \& Cohen, D. (2011). Withinand between-culture variation: Individ- ual differences and the cultural logics of honor, face, and dignity cultures. Journal of Personality and Social Psychology, 100, 507-526. doi:10.1037/a0022151

Markus, H. R., \& Kitayama, S. (1991). Culture and the self: Implications for cognition, emotion, and motivation. Psychological Review, 98, 224-253. doi:10.1037/0033295X.98.2.224

Mojab, S., \& Abdo, N. (2004). Violence in the name of honour: Theoretical and political challenges. Istanbul: Istanbul Bilgi University Press.

Nisbett, R. (2003). The geography of thought: How Asians and Westerners think differently... and why? New York: Free Press.

Oyserman, D. (2011). Culture as situated cognition: Cultural mindsets, cultural fluency and meaning-making. European Review of Social Psychology, 22, 164-214.

Oyserman, D., Coon, H. M., \& Kemmelmeier, M. (2002). Rethinking individualism and collectivism: Evaluation of theoretical assumptions and meta-analyses. Psychological Bulletin, 128, 3-72. doi:10.1037/0033-2909.128.1.3

Oyserman, D., \& Lee, S. W. S. (2007). Priming "culture": Culture as situated cognition. In S. Kitayama \& D. Cohen (Eds.), Handbook of cultural psychology (pp. 255-279). New York: Guilford.

Oyserman, D., \& Lee, S. W. S. (2008a). Does culture influence what and how we think? Effects of priming individualism and collectivism. Psychological Bulletin, 134, 311-342. doi:10.1037/00332909.134.2.311

Oyserman, D., \& Lee, S. W. S. (2008b). A situated cognition perspective on culture: Effects of priming cultural syndromes on cognition and motivation. In R. M. Sorrentino \& S. Yamaguchi (Eds.), Handbook of motivation and cognition across cultures (pp. 237-265). San Diego, CA: Elsevier.

Oyserman, D., \& Sorensen, N. (2009). Understanding cultural syndrome effects on what and how we think: A situated cognition model. In R. Wyer, Y.-Y. Hong, \& C.-Y. Chiu (Eds.), Understanding culture: Theory, research and application (pp. 2552). New York: Psychology Press.

Pitt-Rivers, J. (1965). Honor and social status. In J. G. Peristiany (Ed.), Honor and shame: The values of Mediterranean society 
(pp. 19-78). London: Weidenfeld and Nicolson.

Pitt-Rivers, J. (1977). The fate of Shechem or the politics of sex: Essays in the anthropology of the Mediterranean. Cambridge, UK: Cambridge University Press.

Pratt Ewing, K. (2008). Stolen honor: Stigmatizing Muslim men in Berlin. Stanford: Stanford University Press.

Rodriguez Mosquera, P. M., Manstead, A. S. R., \& Fischer, A. H. (2000). The role of honor-related values in the elicitation, experience, and communication of pride, shame, and anger: Spain and the Netherlands compared. Personality and Social Psychology Bulletin, 26, 833-844. doi:10.1177/0146167200269008

Rodriguez Mosquera, P. M., Manstead, A. S. R., \& Fischer, A. H. (2002a). The role of honor concerns in emotional reactions to offences. Cognition $\mathcal{E}$ Emotion, 16, 143163. doi:10.1080/02699930143000167.

Rodriguez Mosquera, P. M., Manstead, A. S. R., \& Fischer, A. H. (2002b). Honor in the Mediterranean and Northern Europe. Journal ofCross-Cultural Psychology,33,1636. doi:10.1177/0022022102033001002

Schwarz, N. (1994). Judgment in a social context: Biases, shortcomings, and the logic of conversation. Advances in Experimental Social Psychology, 26, 123-162.

Schwarz, N. (1996). Cognition and communication: Judgmental biases, research methods, and the logic of conversation. Hillsdale, NJ: Erlbaum.

Schwarz, N. (1999). Self-reports: How questions shape answers. American Psychologist, 54, 93-105. doi:10.1037/0003066X.54.2.93

Schwarz, N. (2007). Attitude construction: Evaluation in context. Social Cognition, 25, 638-656. doi:10.1521/ soco.2007.25.5.638

Schwarz, N., \& Hippler, H. J. (1995). The numeric values of rating scales: A comparison of their impact in mail surveys and telephone interviews. International Journal of Public Opinion Research, 7, 72-74.

Schwarz, N., Knäuper, B., Hippler, B., Noelle-Neumann, E., \& Clark, L. (1991). Rating scales: Numeric values may change the meaning of scale labels. Public Opinion Quarterly, 55, 570-582. doi:10.1086/269282
Schwarz, N., \& Oyserman, D. (2011). Asking questions about behavior: Self-reports in evaluation research. In M. Mark, S. Donaldson, \& B. Campbell (Eds.), Social psychology and evaluation (pp. 244-264). New York: Guilford.

Schwarz, N., Oyserman, D. \& Peytcheva, E. (2010). Cognition, communication, and culture: Implications for the survey response process. In J. A. Harkness, M. Braun, B. Edwards, T. Johnson, L. Lyberg, P. Mohler, et al. (Eds.), Survey methods in multinational, multiregional and multicultural contexts (pp. 177-190). New York: Wiley.

Smith, E. R., \& Semin, G. R. (2004). Socially situated cognition: Cognition in its social context. Advances in Experimental Social Psychology, 36, 53-117. http://dx.doi. org/10.1016/S0065-2601(04)36002-8.

Smith, E. R., \& Semin, G. R. (2007). Situated social cognition. Current Directions in Psychological Science, 16, 132-135. doi:10.1111/j.1467-8721.2007.00490.x

Sev'er, A., \& Yurdakul, G. (2001). Culture of honor, culture of change: A feminist analysis of honor killings in rural Turkey. Violence against Women, 7, 964-998. doi: $10.1177 / 10778010122182866$

Sperber, D., \& Wilson, D. (1995). Relevance: Communication and cognition ( $2^{\text {nd }}$ ed.). Oxford: Blackwell.

Stevenson, H. W., \& Stigler, J. W. (1992). The learning gap. New York: Simon \& Schuster.

Stewart, F. (1994). Honor. Chicago: University of Chicago Press.

Suzuki, N., \& Yamagishi, T. (2004). An experimental study of self-effacement and self-enhancement among the Japanese. Japanese Journal of Social Psychology, 20, 17-25.

Swann, W., Pelham, B., \& Krull, D. (1989). Agreeable fancy or disagreeable truth? Reconciling self-enhancement with self-verification. Journal of Personality and Social Psychology, 57, 782-791. doi:10.1037/0022-3514.57.5.782

Triandis, H. C. (1989). The self and social behavior in differing cultural contexts. Psychological Review, 96, 506-520. doi:10.1177/0022022194252007

Uskul, A. K., Cross, S., Gercek-Swing, B., Sunbay, Z., \& Ataca, B. (2012). Honor bound: The cultural construction of honor in 
Turkey and the Northern U.S. Journal of Cross-Cultural Psychology, 43, 1131-1151.

Uskul, A. K., \& Oyserman, D. (2006). Question comprehension and response: Implications of individualism and collectivism. In B. Mannix, M. Neale, \& Y. Chen (Eds.), Research on managing groups and teams: National culture \& groups (Vol. 9, pp. 177-206). Oxford: Elsevier Science Press.

Vandello, J. A., \& Cohen, D. (2003). Male honor and female fidelity: Implicit cultural scripts that perpetuate domestic violence. Journal of Personality and Social Psychology, 84, 997-1010. doi:10.1037/00223514.84.5.997
Vandello, J. A., Cohen, D., Granson, R., \& Franiuk, R. (2009). Stand by your man: Indirect cultural prescriptions for honorable violence and feminine loyalty. Journal of Cross-Cultural Psychology, 40, 81-104. doi:10.1177/0022022108326194

Yamagishi, T., \& Yamagishi, M. (1994). Trust and commitment in the United States and Japan. Motivation and Emotion, 18, 129-166. doi:10.1007/BF02249397

Yamaguchi, S. (1994). Collectivism among the Japanese: A perspective from the self. In U. Kim, H. C. Triandis, C. Kagitcibasi, S.-C. Choi, \& G. Yoon (Eds.), Individualism and collectivism: Theory, method, and applications (pp. 175-188). London: Sage. 